\title{
Supersonic Ramjet behind the Aft of the Flying Vehicle
}

\author{
Yu.V. Tunik \\ Institute of Mechanics, Lomonosov Moscow State University, \\ Moscow, 119192, Russia \\ tunik@imec.msu.ru
}

\begin{abstract}
The scheme of a supersonic ramjet, the combustion chamber of which is located behind the end wall of the aft of the flying vehicle, is considered. A numerical experiment is being carried out to simulate the combustion of hydrogen at an altitude of $16 \mathrm{~km}$ with a flight Mach number equal to 9. It is shown that the proposed engine scheme implements diffusion combustion, which under similar flight conditions is several times higher than continuous detonation combustion of hydrogen in a nozzle direct-flow combustion chamber in terms of the efficiency, specific thrust and impulse.
\end{abstract}

Keywords: hydrogen, aft combustion chamber, diffusion combustion, efficiency, numerical experiment

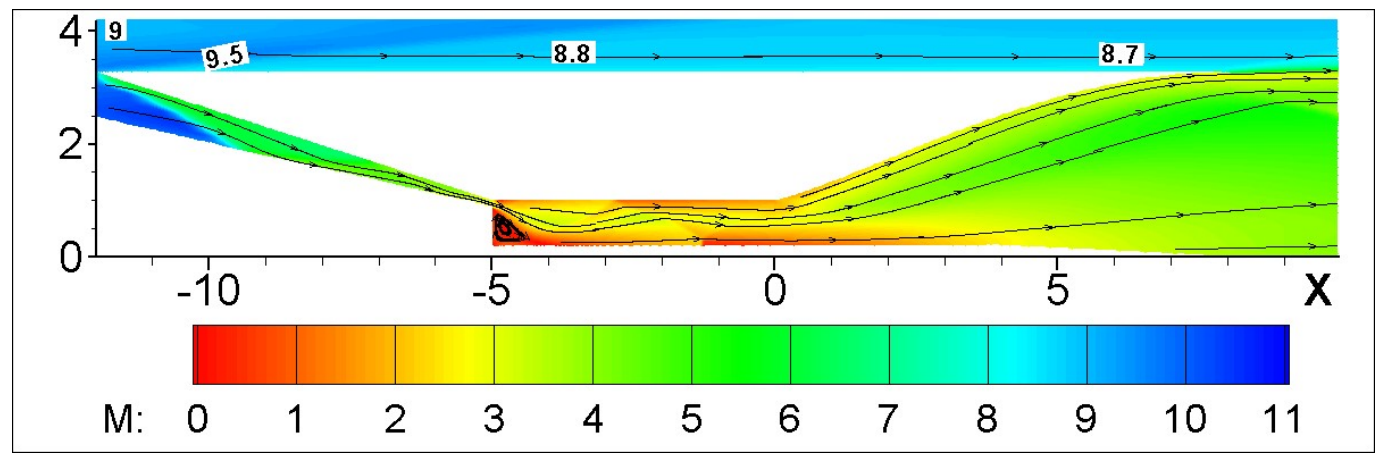

The supersonic ramjet scheme and Mach number behind the aft of the flying vehicle

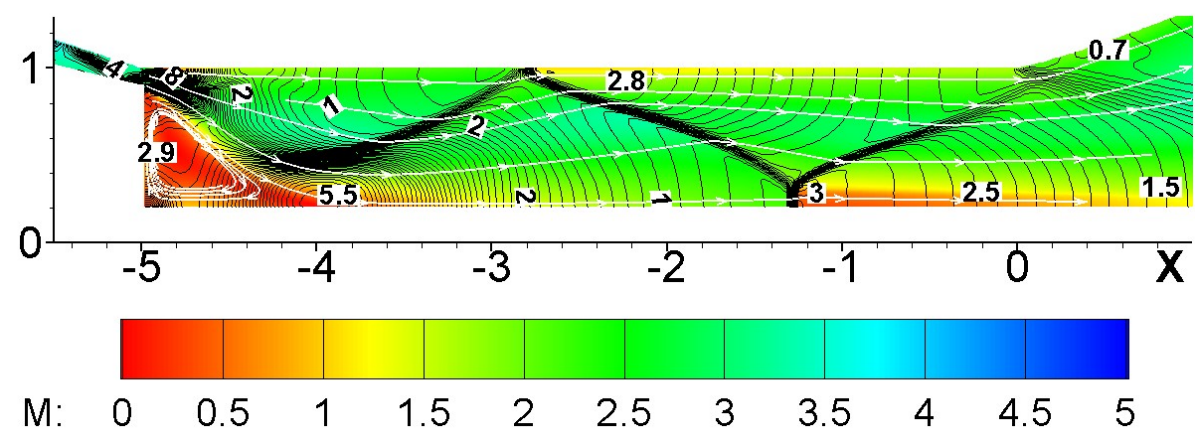

Streamlines, isobars and pressure on the ground of the Mach number in combustion chamber 
УДК 536.5.001.24

\title{
Сверхзвуковой ПВРД за кормой летательного аппарата
}

\author{
Ю.В. Туник \\ НИИ механики, Московский Государственный Университет им. М.В. Ломоносова, \\ Россия, Москва, 119192, Мичуринский проспект д.1 \\ tunik@imec.msu.ru
}

\begin{abstract}
Аннотация
Рассматривается схема прямоточного сверхзвукового воздушно-реактивного двигателя, камера сгорания которого расположена за торцевой стенкой кормы летательного аппарата. Проводится численный эксперимент по моделированию горения водорода на высоте 16 км при полетном числе Маха равном 9. Показано, что в предлагаемой схеме двигателя реализуется диффузионное горение, которое в аналогичных условиях полета в разы превосходит непрерывное детонационное горение водорода в сопловой прямоточной камере сгорания по КПД, удельной тяге и импульсу.

Ключевые слова: водород, кормовая камера сгорания, диффузионное горение, КПД, численный эксперимент
\end{abstract}

\section{1. Введение}

Желание использовать преимущества термодинамического цикла с детонацией Чепмена-Жуге в сверхзвуковых прямоточных воздушно-реактивных двигателях послужило толчком к разработке импульсных детонационных двигателей. В литературе наибольшее внимание уделяется устройствам с многоканальными камерами горения и вращающейся системой клапанов [1-4]. В действительности подобные устройства только условно можно отнести к прямоточным воздушно-реактивным двигателям на детонационном горении. В [5] предложена бесклапанная камера с импульсным детонационным горением, которая располагается за кормой обтекаемого летательного аппарата. Топливо подается в воздухозаборник из кормовой части, которая одновременно является центральным телом воздухозаборника. Детонация принудительно, периодически инициируется у торцевой стенки кормы или вблизи выхода из камеры сгорания. Расчеты и эксперименты показали, что «такое устройство не может должным образом использовать преимущества физических процессов, связанных с детонационным горением». Имеются в виду результаты Я.Б. Зельдовича [6]. Судя по открытым публикациям, эта схема [5] не получила дальнейшего развития.

В данной работе исследуется горение водорода в аналогичной прямоточной камере сгорания на высоте 16 км при скорости набегающего воздушного потока, соответствующей полетному числу Маха равному 9. Интерес к данной, а точнее близкой к ней схеме обусловлен кажущейся простотой смешения топлива с воздухом в донной области сверхзвукового летательного аппарата. Цель работы - установить возможность генерации тяги без принудительного инициирования горения водорода в простейшей установке, расположенной за торцевой стенкой кормовой части летательного аппарата, и оценить величину этой тяги.

\section{2. Схема силовой установки}

Вариант соответствующей осесимметричной двигательной установки представлен на рис. 1. Сужающуюся кормовую часть летательного аппарата можно рассматривать как центральное тело воздухозаборника с конической внутренней поверхностью. Камера сгорания 
начинается от торцевой стенки радиуса $R_{w}$ и переходит в расширяющееся сопло. В камере в качестве основы конструкции, удерживающей внешнее тело, размещается центральное тело «цилиндр-конус» радиуса $R_{b}$. Камеру сгорания продолжает сопло, контур которого задается степенной функцией синусоиды. Показатель степени определяется положением точки перегиба контура. Воздухозаборник, камера сгорания и выхлопное сопло встроены во внешнее тело, которое наряду с кормовой частью летательного аппарата используется в качестве резервуара с топливом. В данной работе радиусы обтекаемого летательного аппарата, входа в воздухозаборник и выходного сечения сопла считаются равными и задаются числом Маха $\mathrm{M}_{n}$, на которое рассчитано сопло по одномерной классической теории при показателе адиабаты равном 1.4. На рис. 1 и далее все длины и расстояния отнесены к радиусу минимального сечения сопла $r_{0}=10 \mathrm{~cm}$. В расчетах $\mathrm{M}_{n}=4$, так что радиус обтекаемого аппарата $R_{a} \approx 33 \mathrm{~cm}$.

В отличие от [5] топливо, а конкретно, водород может подаваться через торцевую стенку камеры сгорания и внутреннюю стенку внешнего тела. Тяга должна создаваться за счет давления продуктов горения на торцевую стенку кормы и на стенку расширяющего сопла.

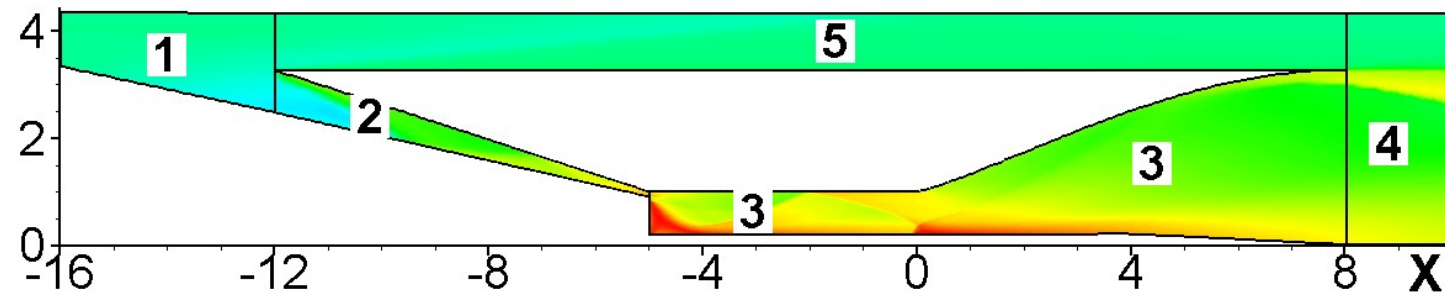

$\mathrm{M}: \mathrm{O}$

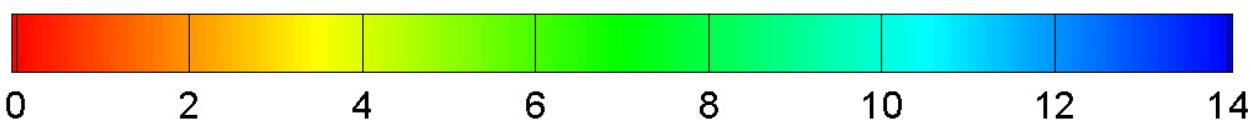

Рис. 1. Пять частей расчетной области на фоне числа Маха в установившемся воздушном потоке на высоте 16 км при числе Маха $\mathrm{M}_{0}=9$

\section{3. Запуск установки в сверхзвуковом воздушном потоке}

Первая задача - это запуск установки. В данной работе, как и в [7], запуск осуществляется в два этапа. Вначале установка вместе с обтекаемым аппаратом разгоняется в воздушной атмосфере на высоте $H=16$ км из состояния покоя до скорости, соответствующей заданному числу Маха $\mathrm{M}_{0}=9$. Ниже давление отнесено к давлению нормальной приземной атмосферы $p_{0}=0.101325$ МПа, время $t-\kappa t_{0}=r_{0} / U_{0}$, где $U_{0}=\sqrt{p_{0} / \rho_{0}}, \rho_{0}-$ плотность воздуха при нормальном давлении $p_{0}$ и температуре $T_{H}=216.7 \mathrm{~K}$ на высоте $H$.

\section{1. Постановка и метод решения задачи}

Воздушный поток набегает слева (см. рис. 1). В исходном состоянии скорость газа всюду равна нулю, давление и плотность во всей расчетной области имеют значения, соответствующие окружающей атмосфере на высоте $H: p_{H}$ и $\rho_{H}$. Разгон летательного аппарата вместе с установкой до заданного числа Маха моделируется увеличением скорости газа во всей расчетной области на величину, которая определяется заданным и постоянным ускорением.

На левой границе давление и плотность не меняются в течение всего расчета. На стенках и оси симметрии ставятся условия непротекания, на верхней границе нулю равны производные параметров по оси ординат. На правой границе при дозвуковой скорости задается давление $p_{H}$, а при сверхзвуковой - производные параметров по оси абсцисс полагаются равными нулю. 
Текущие параметры как внешнего, так и внутреннего течения рассчитываются на основе нестационарных двумерных уравнений Эйлера для осесимметричного случая с использованием схемы С.К.Годунова и ее $\beta$-модификации второго порядка точности по пространственным переменным [11-12]. В расчетах число Куранта, ограничивающее шаг по времени, равно 0.4 и 0.2 для схемы первого и второго порядка, соответственно. Расчетная область разбивается на 5 частей: подобласть встречного течения до входа в воздухозаборник (1), полость воздухозаборника (2), камера сгорания и сопло (3), а также подобласти следа и внешнего течения: (4) и (5).

\section{2. Результаты численного моделирования}

В воздухозаборнике рассматриваемого устройства происходит снижение скорости воздушного потока на входе в камеру сгорания. Чем больше радиус кормы $R_{w}$, тем меньше эта скорость и тем проще смешать топливом с воздухом. Успешный запуск, при котором поток на выходе из сопла разгоняется до сверхзвуковой скорости и, в то же время, остается сверхзвуковым в воздухозаборнике, реализуется при $R_{w}=0.9$. На рис. 1 представлены результаты расчета по схеме второго порядка точности на основной, сравнительно грубой сетке, фрагменты которой представлены на рис. 2. При переходе из воздухозаборника в камеру сгорания размер расчетной ячейки по оси абсцисс удваивается (рис. 2, б). В результате в области камеры сгорания и сопла формируется сетка $250 \times 0$ ячеек.
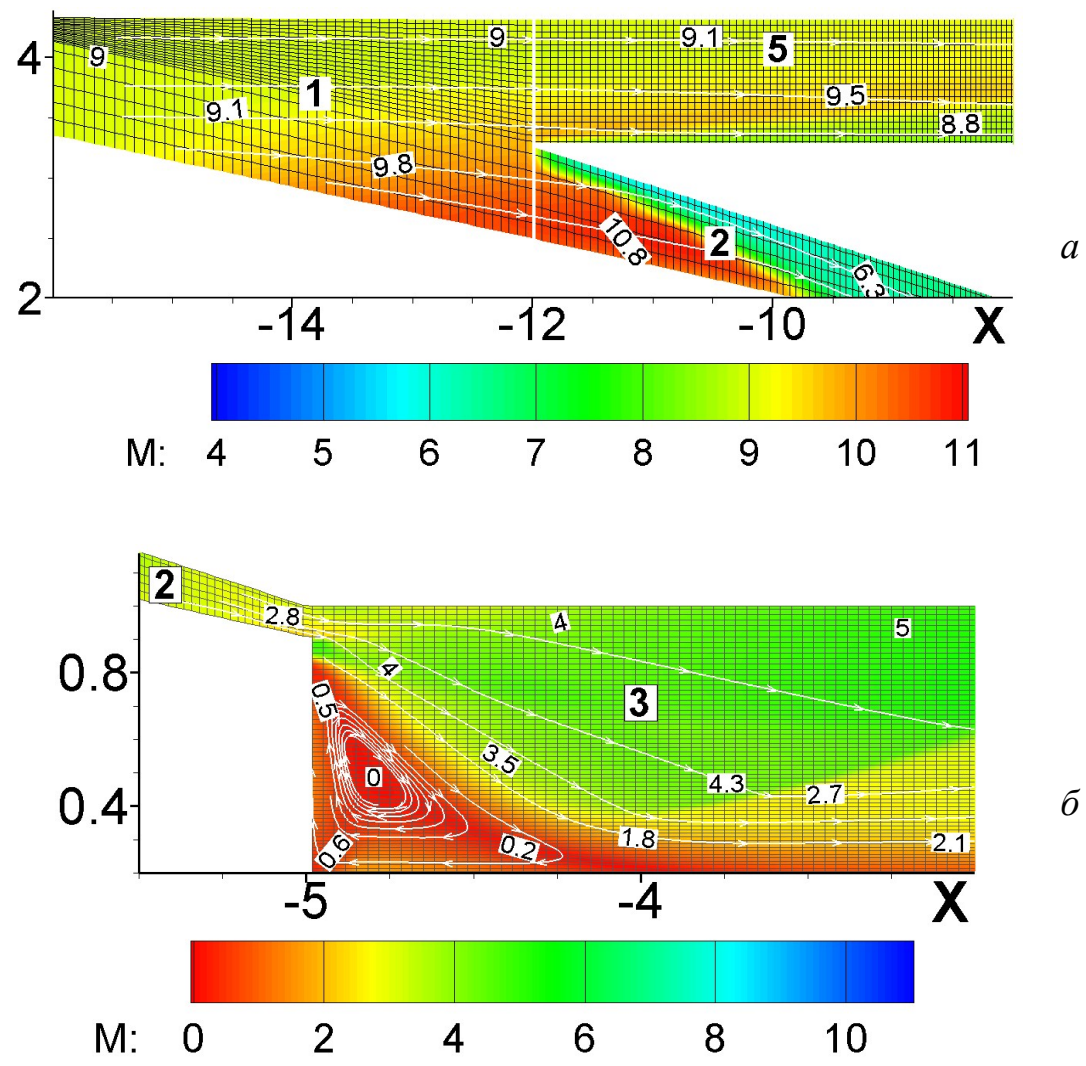

Рис. 2. Фрагменты основной расчетной сетки и линии тока на фоне числа Маха в подобласти 1,2 и 5 (a) и у границы раздела 2 и 3 (б) на фоне числа Маха в установившемся воздушном потоке

За угловой точкой на контуре обтекаемого аппарата поток разворачивается в волне разрежения (рис. 2,a). Передняя кромка воздухозаборника разделяет набегающий поток на внутренний и внешний. В волне разрежения число Маха растет, а давление падает. Затем поток тормозится до числа Маха менее 3 (рис. 3, a), а давление и температура растут за косыми скачками уплотнения (рис. 3,6 и 3,6 ). 

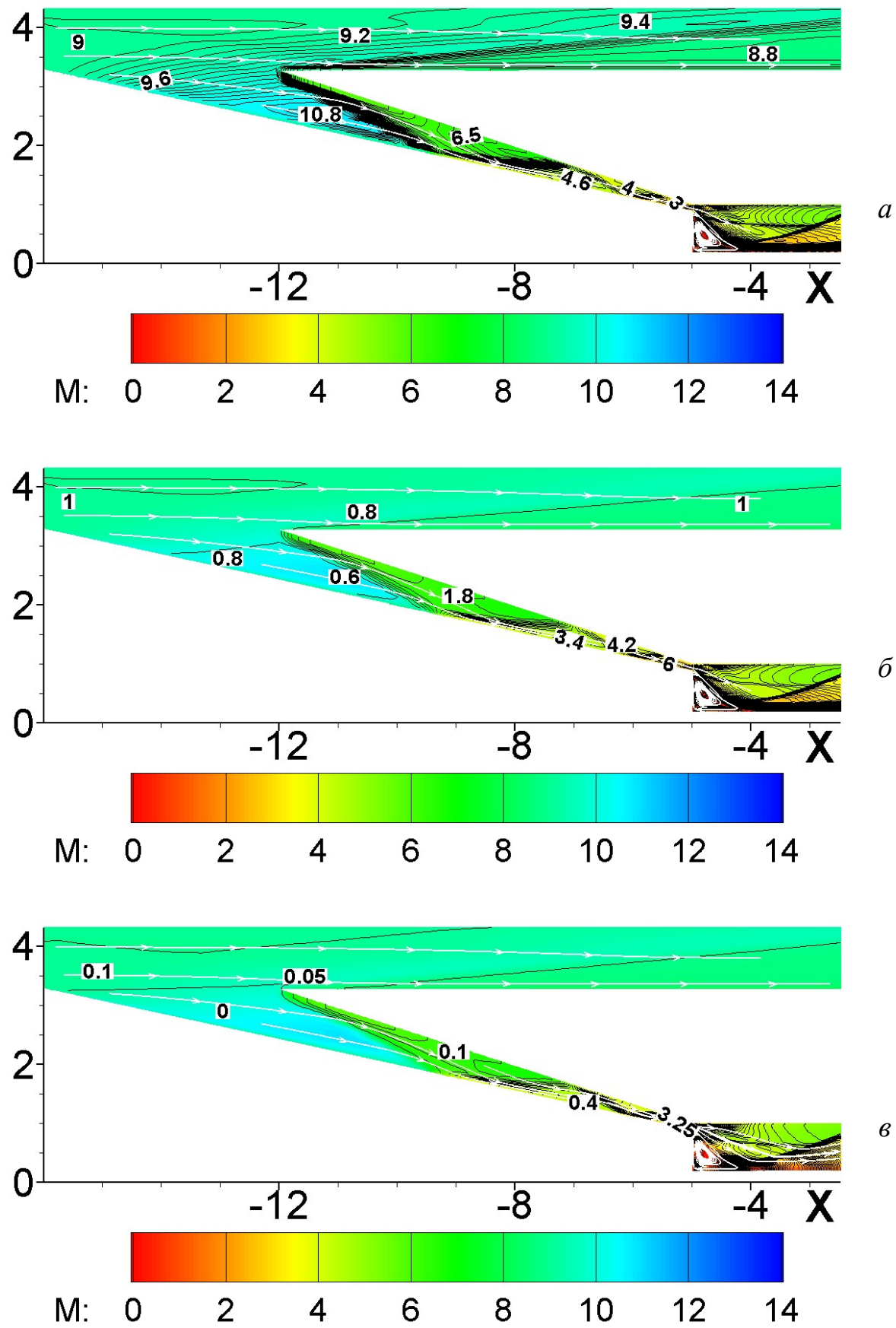

Рис. 3. Линии тока, постоянного числа Маха $(a)$, изотермы $T / T_{H}$ (б) и изобары (в) в воздухозаборнике на фоне числа Маха в установившемся воздушном потоке при $R_{w}=0.9$

К моменту входа в камеру сгорания число Маха потока падает примерно до 2.7 (рис. $4, a)$, давление увеличивается более чем в 40 (рис. 4, б), а температура более чем в 6 раз (рис. 4,8 ) по сравнению с параметрами в набегающем потоке. В донной области летательного аппарата формируется возвратное вихревое течение, а над поверхностью центрального тела - «висячий» подковообразный скачок уплотнения с регулярным отражением от внутренней продольной стенки камеры сгорания.

Аналогичную картину течения дают расчеты по схеме первого порядка точности (рис. 5). Качественное отличие заключается в положении точки отражения подковообразного скачка уплотнения с продольной стенкой камеры сгорания. 


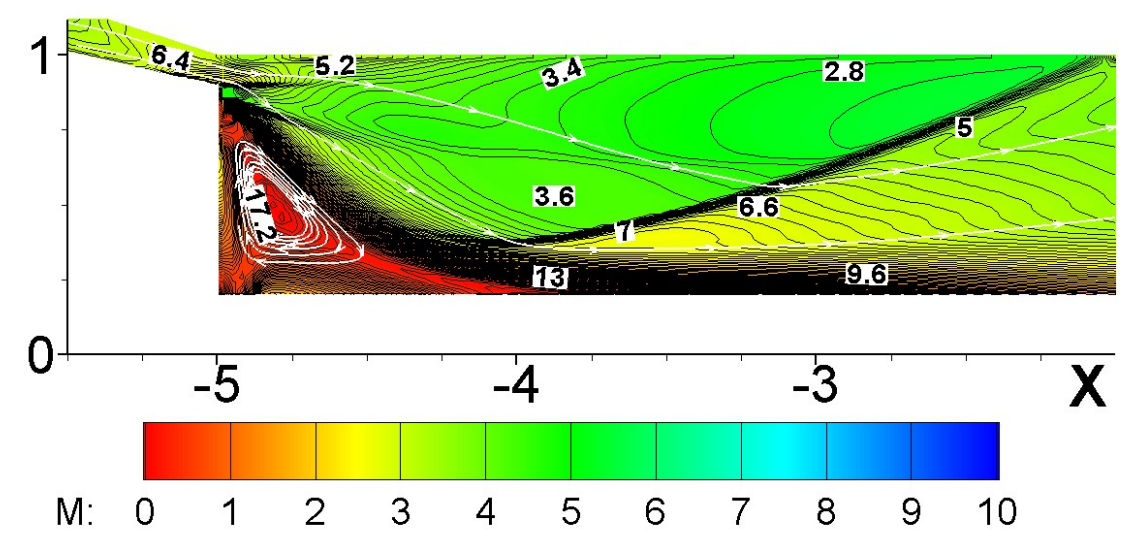

$a$

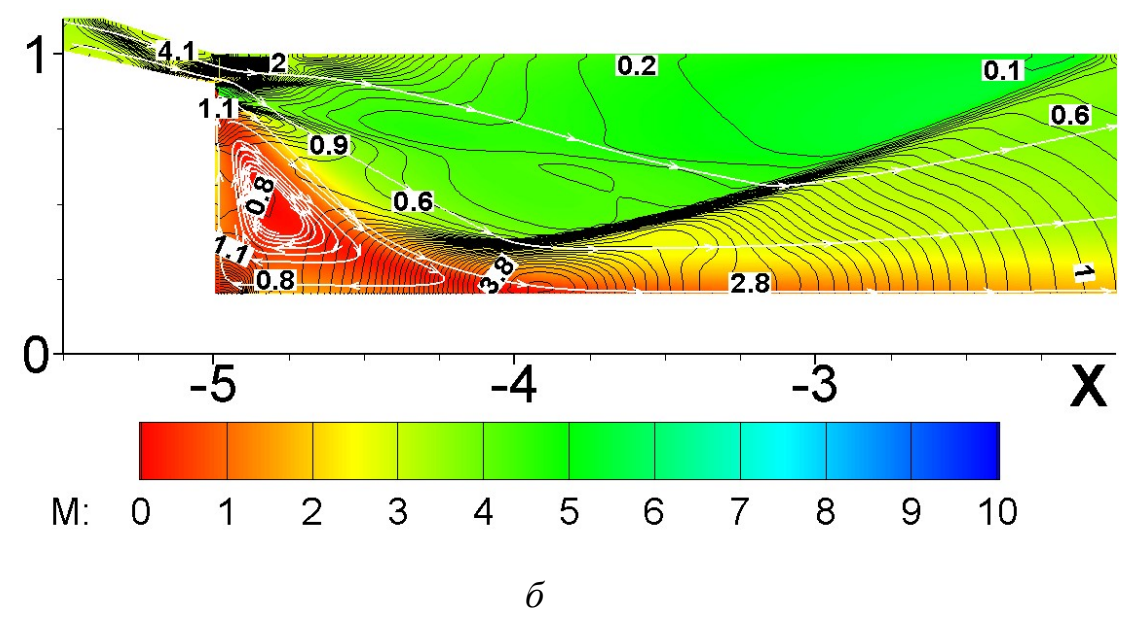

Рис. 4. Линии тока, изотермы $T / T_{H}(a)$ и изобары (б) в донной области летательного аппарата на фоне числа Маха в установившемся воздушном потоке при $R_{w}=0.9$

В результате использования грубой расчетной сетки и, как следствие, низкой точности расчета осесимметричной волны разрежения за углом обтекаемого тела массовый поток воздуха, попадающего в камеру сгорания, оказывается на $18 \%$ больше, в расчете по схеме второго порядка. Давление за системой косых скачков уплотнения в конце воздухозаборника в некоторой фиксированной точке (рис. $5, a$ ) на $70 \%$ выше, чем в случае расчета по схеме второго порядка (см. рис. $4, a$ ). Удвоение числа расчетных ячеек по каждому из направлений (рис. 5, б) снижает это различие до 3.5 и $17 \%$, соответственно, а при увеличении числа ячеек по каждому направлению в 4 раза массовый расход газа и давление в выбранной точке становятся ниже на 5.5 и $7.5 \%$, чем в случае использования схемы второго порядка и грубой сетки (рис. 5,8$)$. При этом погрешность вычисления массового расхода газа в подобласти 2 и 3 не превышает 0.4 \% во всех четырех случаях. На разницу давления в фиксированных точках расчетной области влияет степень размывания скачков уплотнения. Если, например, выделенная точка в случае большого числа ячеек или расчета по схеме второго порядка располагается строго между косыми скачками уплотнения, то на более грубой сетке она может попасть в область размытой структуры ударной волны.

При расчете полной энтальпии в подобласти 2 ошибка не превышает $0.7 \%$. Наилучший результат имеет расчет по схеме первого порядка при наибольшем числе расчетных ячеек. Сопоставимые по точности результаты дает расчет по схеме второго порядка на грубой сетке. В камере сгорания наибольшая погрешность вычисления полной энтальпии возникает в области вихревого течения за торцевой стенкой. В расчетах по схеме первого порядка погрешность не превосходит $15 \%$, а в случае схемы второго порядка достигает 7 и $20 \%$, соответственно, при $\beta=0.5$ и $\beta=1$ (см. [11-12]). 

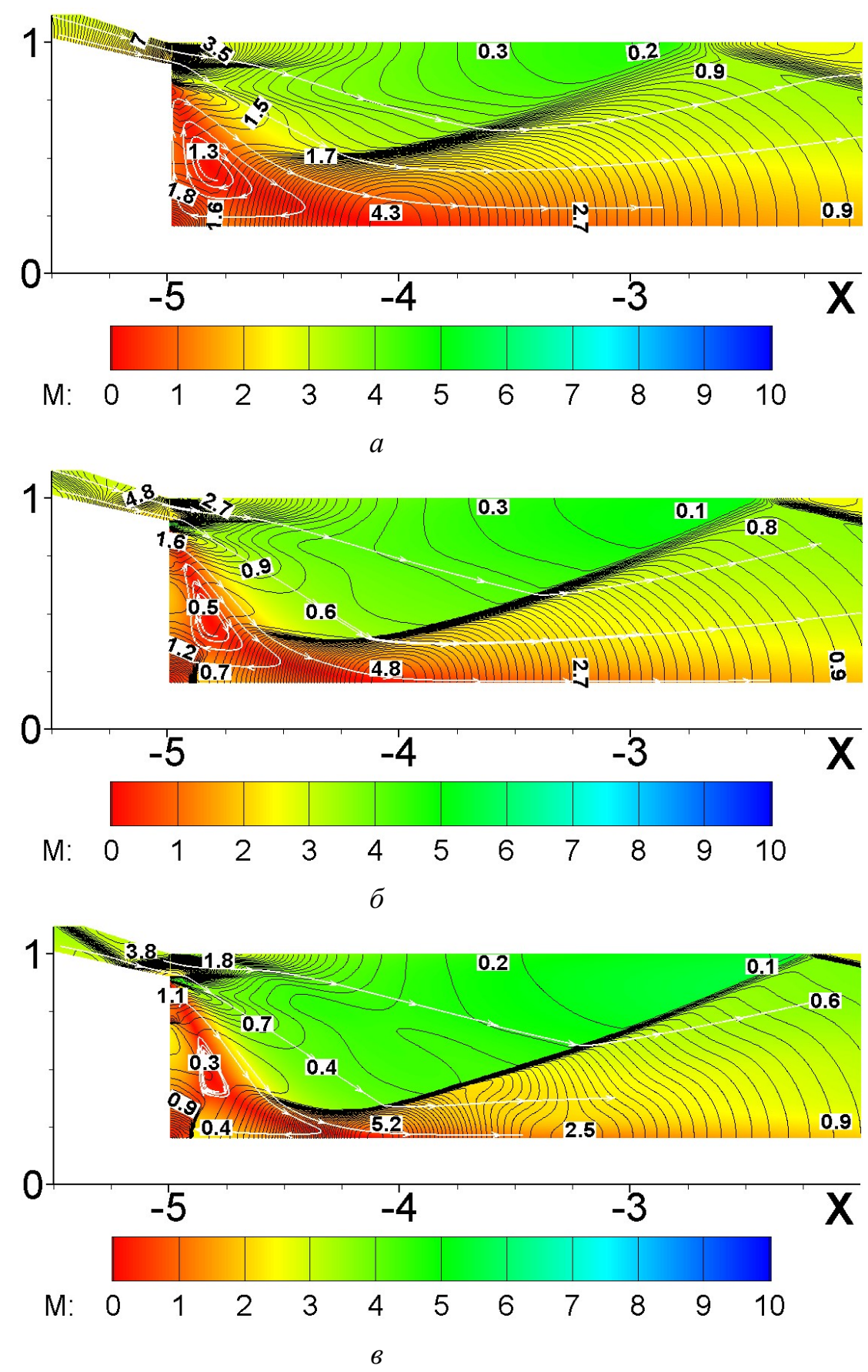

Рис. 5. Линии тока, изобары и давление в установившемся потоке за торцевой стенкой кормы на фоне числа Маха по схеме первого порядка на грубой сетке $(a)$, при удвоении (б) и увеличении в 4 раза (в) числа ячеек по каждому направлению $\left(R_{w}=0.9\right)$

Таким образом, схема второго порядка точности на грубой сетке обеспечивает погрешность на уровне расчета по схеме первого порядка точности на сетке, число ячеек которой увеличено приметно в 3 раза по каждому из направлений.

При радиусе торцевой стенки кормы $R_{w} \geq 0.94$ запустить устройство не удается: в воздухозаборнике формируется ударная волна, выходящая в набегающий поток (рис. 6). Очевидно, что в этом случае подача топлива приведет к выбросу продуктов горения во внешний поток. Это увеличит аэродинамическое сопротивление летательного аппарата и не позволит получить тягу. Из рассмотренных вариантов успешный запуск с установившимся сверхзвуковым течением в воздухозаборнике реализуется в устройстве с радиусом торцевой стенки 
кормы $R_{w}=0.9$. В следующем разделе инжекция и горение водорода рассматривается при $R_{w}=0.9$.

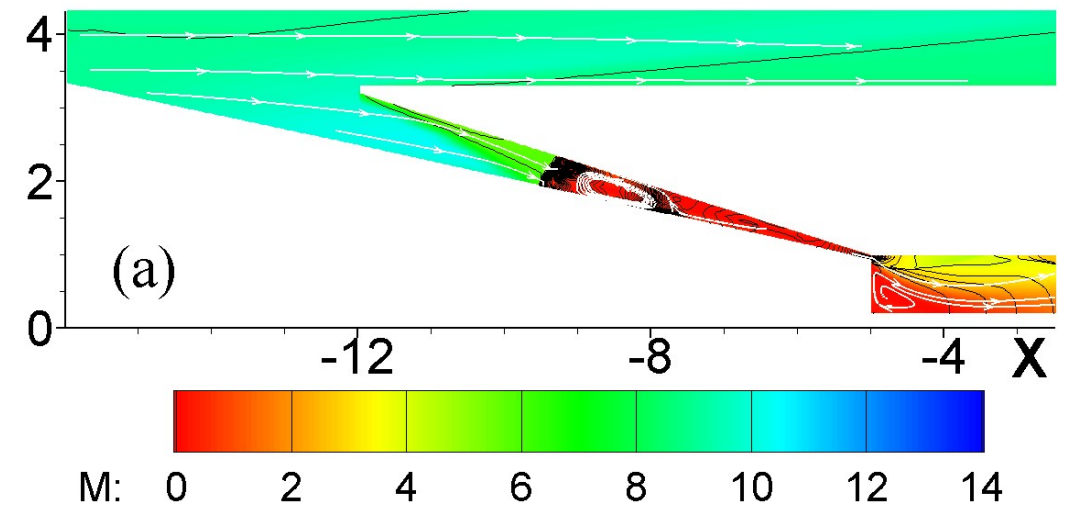

$a$

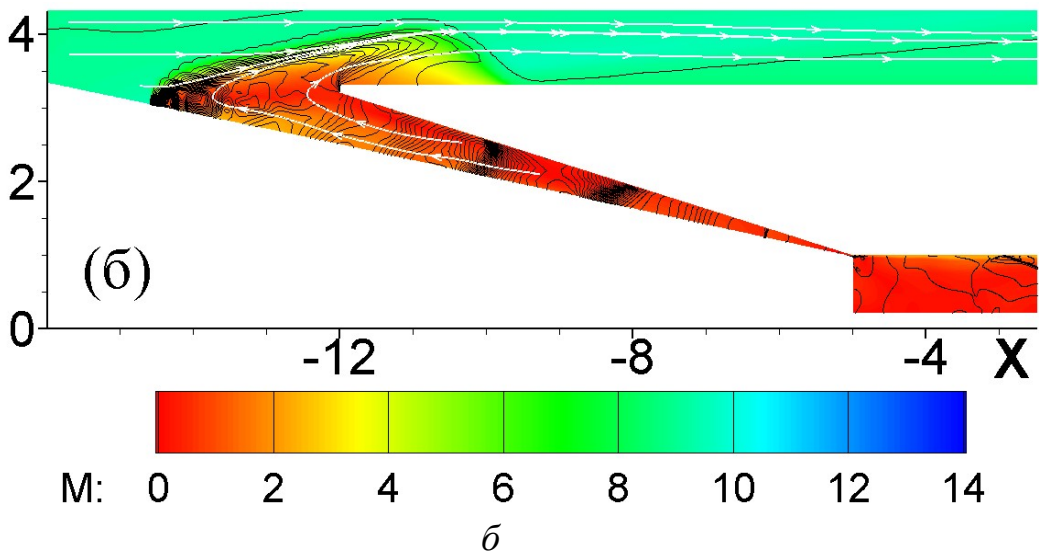

Рис. 6. Линии тока и изобары на фоне числа Маха в различные моменты запуска при $R_{w}=0.94$ (a) и 0.98 (б)

\section{4. Инжекция и горение водорода}

Инжекция водорода осуществляется после стабилизации течения в задаче запуска установки в воздушном потоке. Установившееся решение задает начальное распределение параметров в задаче с инжекцией и горением водорода. Расчет проводится в области, из которой исключена подобласть 1 встречного потока (см. рис. 1 и 9). Предполагается, что водород поступает через перфорированные стенки и смешивается с воздухом в камере сгорания. Реальная картина инжекции топлива через отдельные отверстия моделируется заданием притока массы, импульса и энергии потока водорода с некоторой части поверхности стенки. Доля площади отверстий на этой части поверхности задается параметром перфорации $\delta$. Давление, плотность и скорость инжектируемого потока рассчитываются по адиабатическим формулам, локальному давлению на поверхности стенки $p$, давлению $p *$ и температуре $T *$ в резервуаре хранения водорода. Если $p>p *$, инжекция прекращается, если $p$ меньше критического давления для заданного $p *$, то истечение водорода происходит со звуковой скоростью. Давление $p *$ и температура $T *$ в резервуарах хранения водорода, площадь перфорированных стенок, параметр перфорации $\delta$, а также угол наклона $\chi$ водородных струй к поверхности перфорированного участка стенки входят в список параметров, определяющих решение задачи горения водорода в камере сгорания.

Тяга $F$ рассчитывается как интеграл проекции на ось абсцисс сил давления по стенкам воздухозаборника, камеры сгорания, выхлопного сопла и центрального тела. Учитывается давление только на твердую часть перфорированной поверхности, доля которой составляет $(1-\delta)$ площади перфорированного участка. Расчеты без учета подобласти 1 не учитывают 
давление на участок обтекаемого аппарата, оставшийся в подобласти 1 (см. рис. 1). Ниже эта поправка, увеличивающая безразмерную величину $F / p_{0} r_{0}^{2}$ примерно на 0.3 , не учитывается в расчетах и не отражается на кривых тяги и импульса.

\section{1. Постановка и метод решения задачи о сжигании водорода}

С учетом возможности торможения потока до дозвуковой скорости и различных условий смешения задача должна решаться на базе уравнений Навье - Стокса. Однако использование уравнений Навье - Стокса или Рейнольдса усложняет моделирование, но не гарантирует высокой точности результатов из-за множества эмпирических констант определяющих соответствующие модели процессов переноса для течения в рассматриваемой установке. В качестве первого приближения, которое позволяет оценить работоспособность устройства, можно использовать уравнения Эйлера. Очевидно, что такую математическую модель нельзя считать корректной, поскольку при численном решении задачи вязкость, теплопроводность и диффузия реального газа заменяются соответствующими величинами, характерными для выбранной численной схемы. Схемы первого порядка могут занижать реальное число Рейнольдса, а схемы второго и более высокого порядка подавляют схемную вязкость, что соответствует высоким значениям числа Рейнольдса. Таким образом, представленные ниже исследования на основе уравнений Эйлера при соответствующих граничных условиях можно трактовать как численный эксперимент и «надеяться, что проведенные расчеты несут и определенную количественную информацию» [13]. С их помощью можно получить предварительную картину течения и оценку энергетической эффективности устройства.

Как и в предыдущем разделе, расчеты проводятся на основе численной схемы С.К. Годунова и ее $\beta$-модификации второго порядка аппроксимации. Используемая кинетическая модель горения водорода [14-15] включает 9 компонент, участвующих в 33 неравновесных обратимых реакциях и хорошо согласуется с результатами расчетов по моделям [16-17]. Теплоемкость и энтальпия смеси рассчитываются по приведенной энергии Гиббса газовых компонентов [18].

\section{2. Результаты численного моделирования по схеме второго порядка}

Перфорированной считается вся поверхность торцевой стенки камеры сгорания с $\delta=0.01$. Водород подается по нормали к стенке. С продольной внутренней стенки камеры сгорания инжекция топлива происходит навстречу потоку под углом $\chi=225^{\circ}$ к оси абсцисс. Перфорированный участок длиной $L=0.2$ и с $\delta=0.025$ начинается с сечения, совпадающего с торцевой стенкой в точке с абсциссой $X=-5$. Расчеты выполняются при $p_{H}=0.1$, $T_{H}=216.7 \mathrm{~K}, p *=5$ и $T *=T_{H}$. Здесь и ниже указаны безразмерные значения давления, которые определяются так же, как и в задаче запуска в воздушном потоке.

Инжекция водорода приводит к перестройке течения. Со временем во всей расчетной области формируется установившееся ярко выраженное струйное течение (рис.7) со сложной ударно-волновой структурой в камере сгорания и вихревым течением в донной области летательного аппарата (рис. $8, a)$.

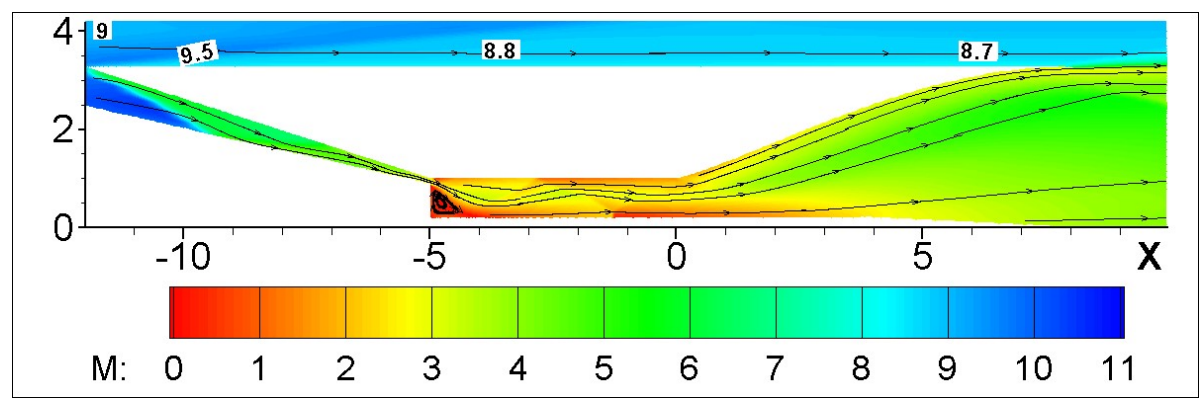

Рис. 7. Линии тока на фоне числа Маха в расчетной области 

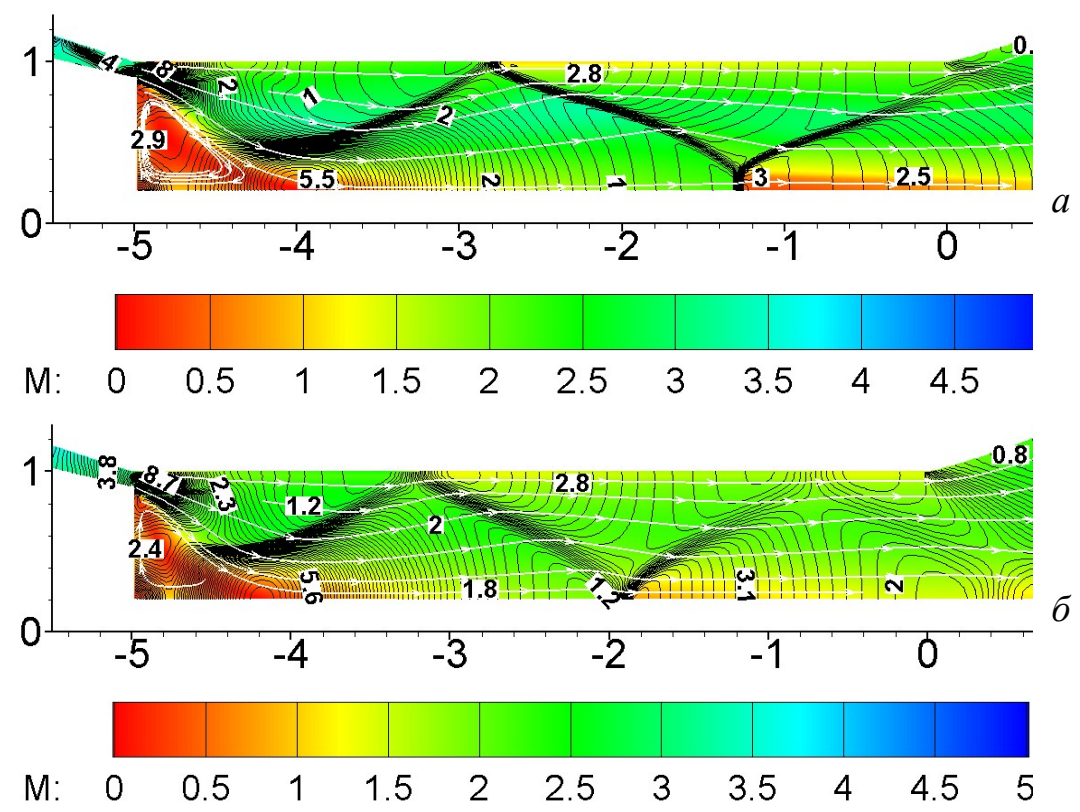

Рис. 8. Линии тока, изобары и давление на фоне числа Маха в камере сгорания:

(a) - расчет по схеме второго порядка, (б) - первого

У продольной стенки камеры образуется цилиндрическая струя несгоревшего водорода (рис. 9, a). Ближе к оси симметрии располагается струя воздуха (рис. 10,a). Между ними зона интенсивного горения с образованием радикала ОН (рис. $11, a)$ и паров воды (рис. $12, a)$. Во второй струе с высоким содержанием $\mathrm{OH}$ и $\mathrm{H}_{2} \mathrm{O}$ сгорает водород, впрыскиваемый с торцевой стенки. Однако значительная его часть не участвует в горении и выносится потоком вдоль поверхности центрального тела. Таким образом, горение происходит в диффузионном режиме.
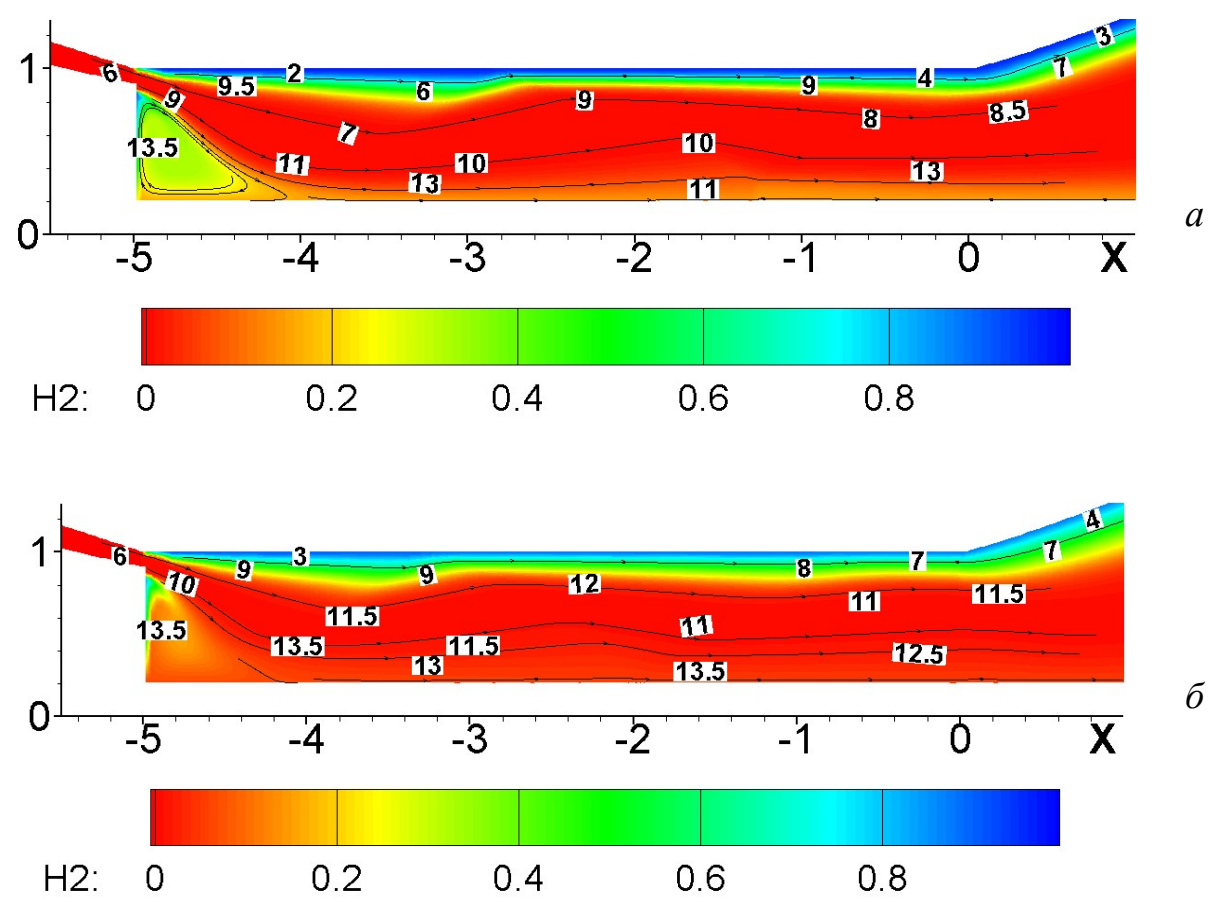

Рис. 9. Линии тока и температура газа в камере сгорания на фоне молярной доли водорода: (a) - расчет по схеме второго порядка, (б) - первого 

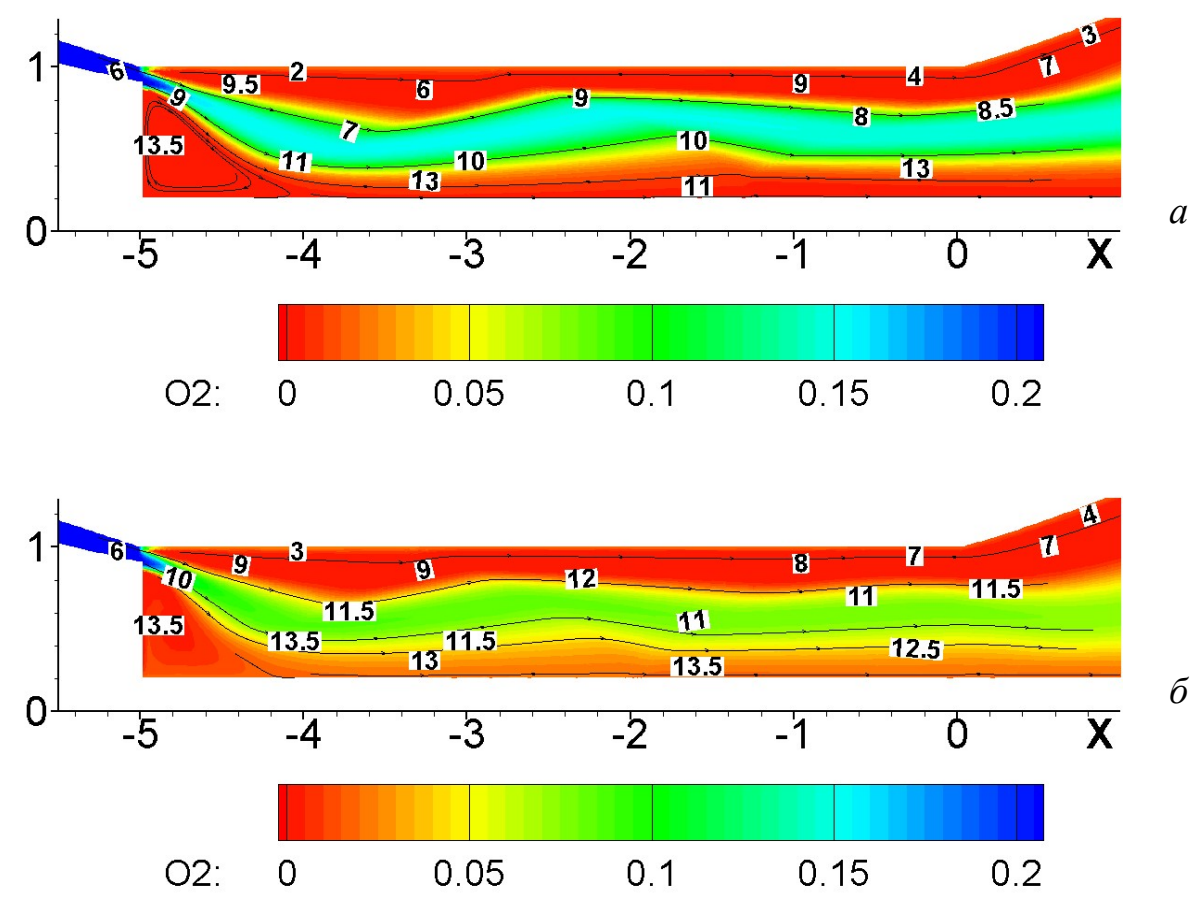

Рис. 10. Линии тока и температура газа в камере сгорания на фоне молярной доли кислорода: (a) - расчет по схеме второго порядка, (б) - первого
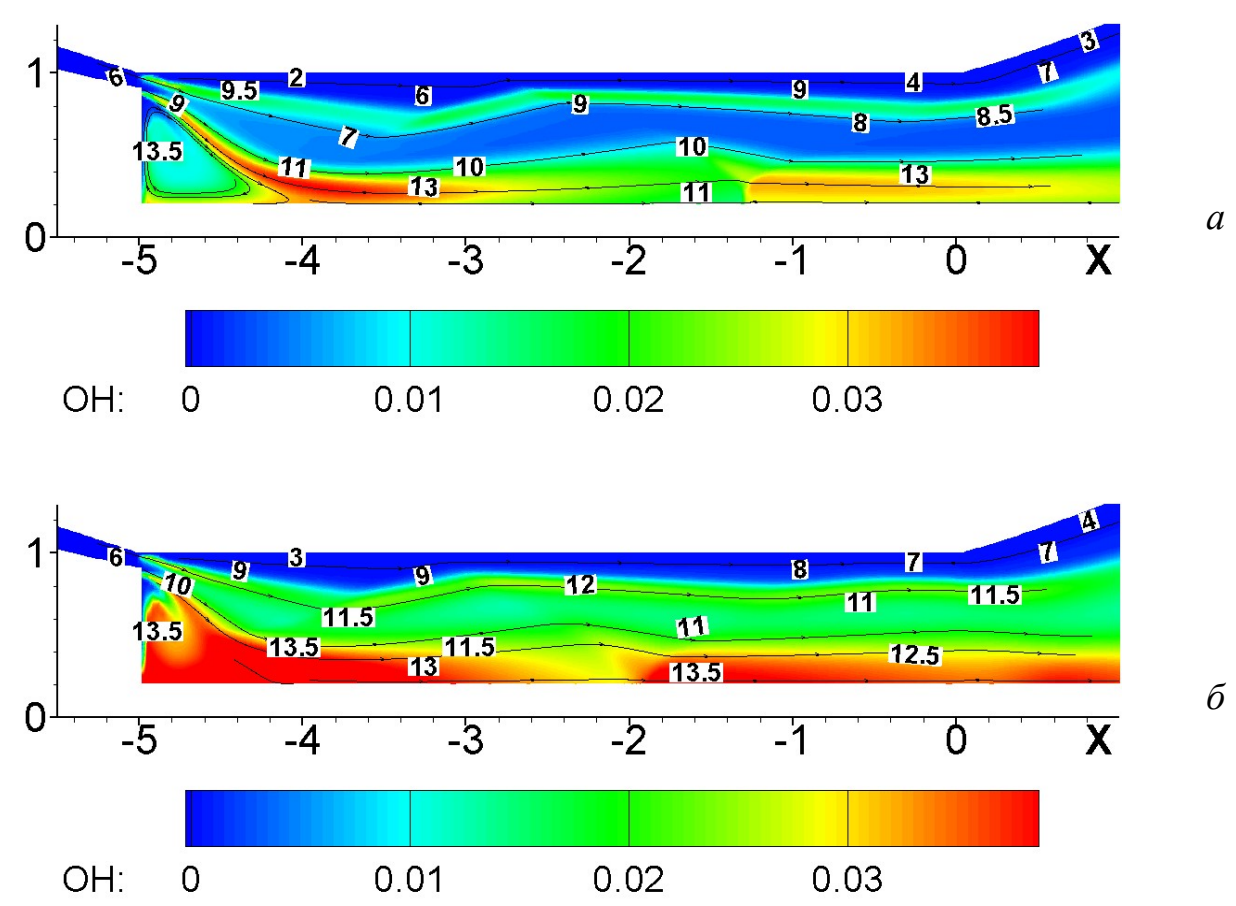

Рис. 11. Линии тока и температура газа в камере сгорания на фоне молярной доли $\mathrm{OH}:(a)$ - расчет по схеме второго порядка, (б) - первого

Суммарный расход водорода $G_{H 2}$ составляет примерно 0.89 кг/с, что по отношению к общему расходу газа $G \approx 16.7$ кг/с (рис. 13) почти точно соответствует стехиометрической смеси $(\varphi \approx 1.0)$. Однако из-за плохого смешения примерно $70 \%$ водорода не участвует в горении. В результате установка обеспечивает суммарную тягу $F \approx 0.826$ т $\approx 8095 \mathrm{H}$ и удель- 
ный импульс (отношение тяги к общему весовому расходу газа) $\boldsymbol{I}_{G} \approx 49.6$ с (рис. 14 , кривые 1). Удельная тяга (отношение тяги к весовому расходу топлива) $\boldsymbol{I} \approx 928 \mathrm{c}$.

Нетрудно понять, что в рассматриваемой установке тяга может быть получена и без сжигания топлива, исключительно за счет инжекции водорода через торцевую стенку кормы. В этом случае тяга и удельный импульс (кривые 3 на рис. 14) создаются за счет давления в донной области обтекаемого аппарата (рис. 15), которое оказывается в два раза ниже, чем при сжигании водорода. Без горения и сопловая часть установки практически не участвует в создании тяги из-за низкого давления в этой области (рис. 16).
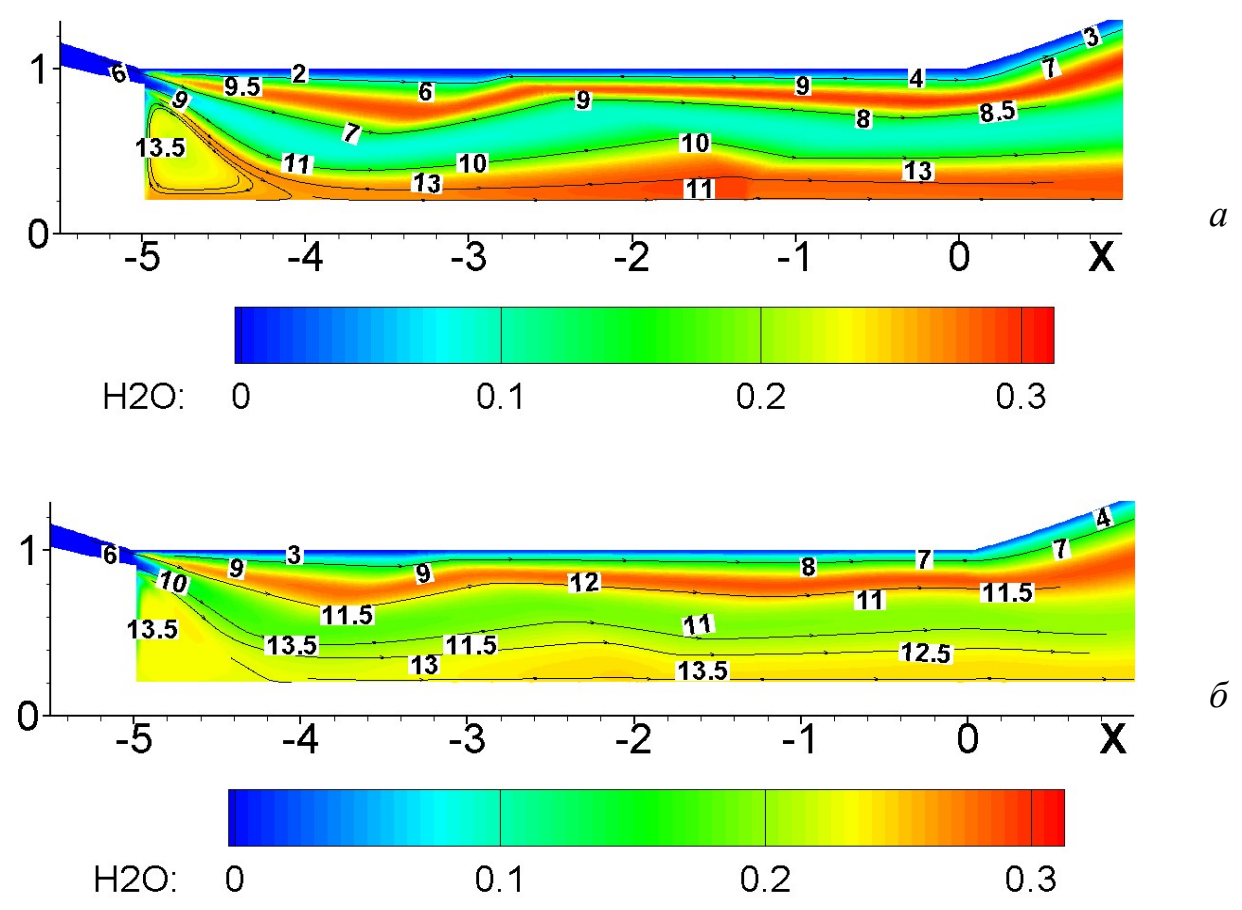

Рис. 12. Линии тока и температура газа в камере сгорания на фоне молярной доли паров воды: $(a)$ - расчет по схеме второго порядка, (б) - первого

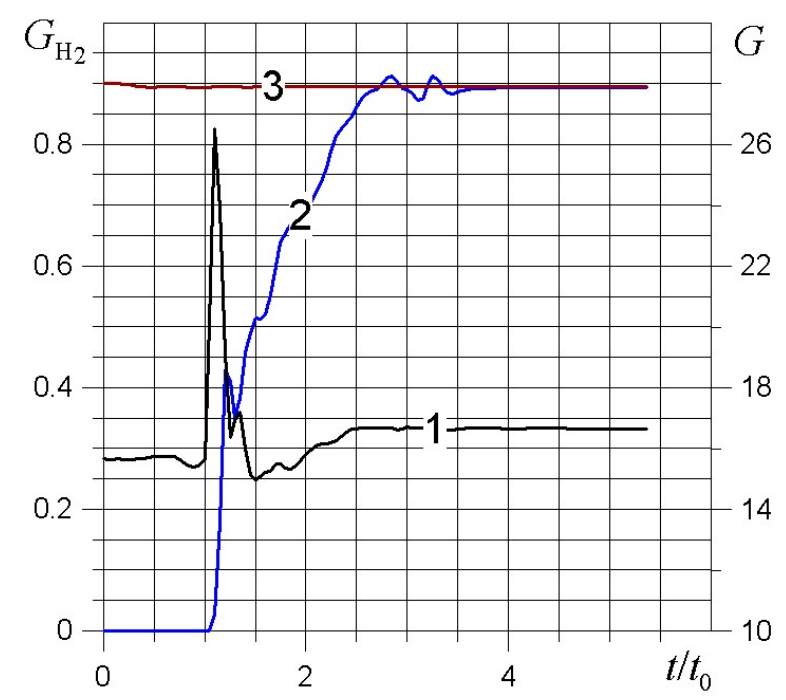

Рис. 13. Массовый расход газа $G$ [кг/с] (кривая 1) и водорода $G_{\mathrm{H} 2}[\kappa г / \mathrm{c}]$ на выходе из сопла (кривая 2), а также при подаче водорода [кг/с] со стенок камеры (кривая $3)$ в процессе формирования установившегося течения 


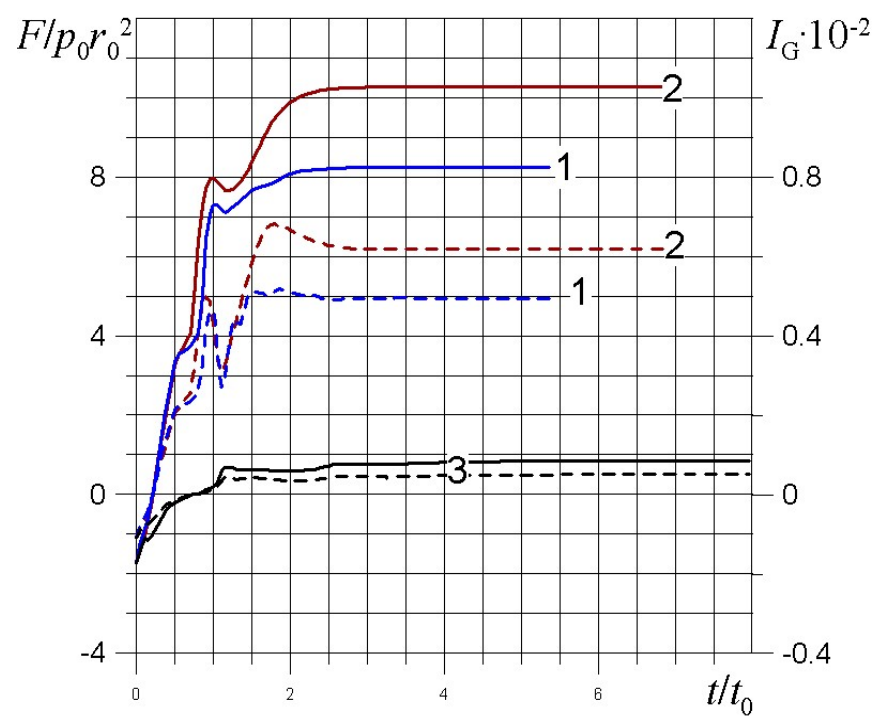

Рис. 14. Изменение тяги $F$ (сплошные кривые) и удельного импульса $\boldsymbol{I}_{\mathrm{G}}$ [c] (пунктир) в процессе формирования установившегося течения по схеме второго (кривые 1) и первого порядка (кривые 2), а также в случае без горения впрыскиваемого водорода (кривые 3 )
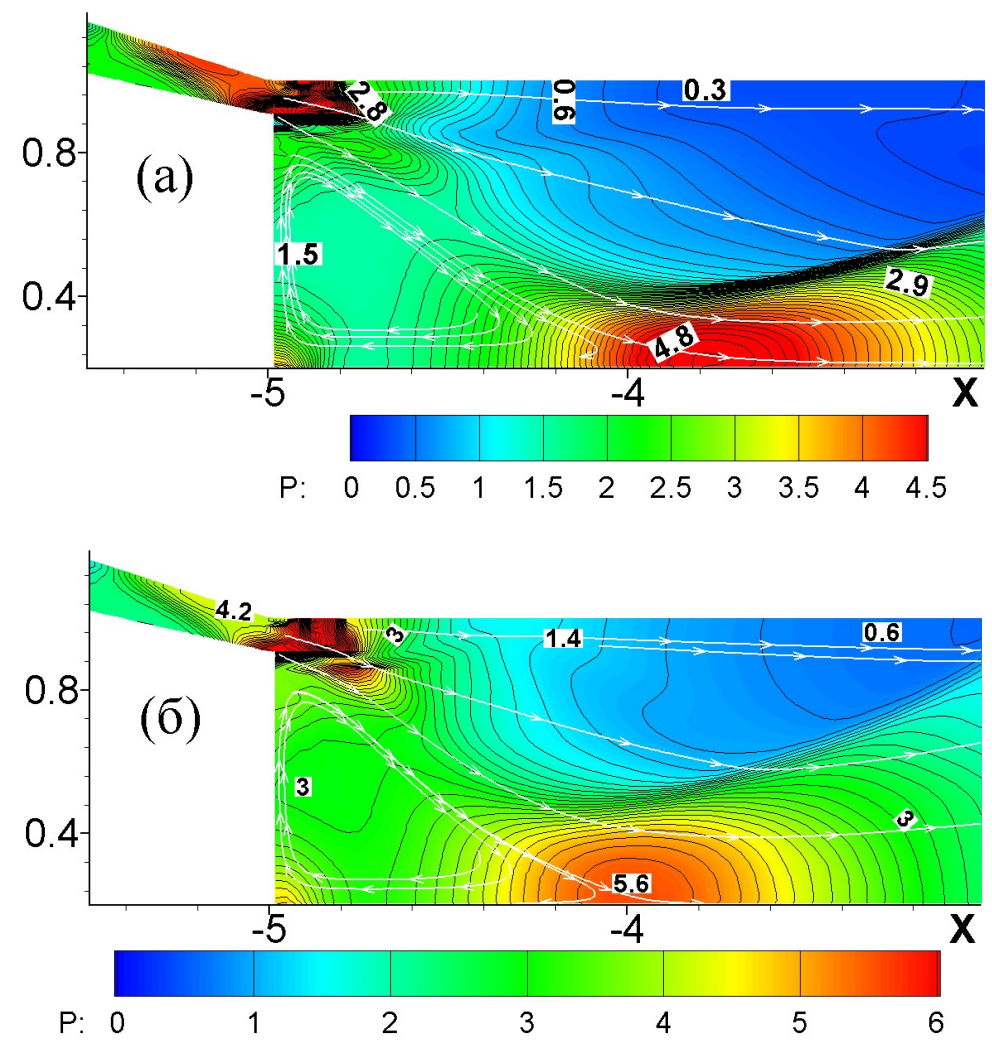

Рис. 15. Давление за торцевой стенкой в отсутствии горения (а) и при сжигании водорода (б)

Интересно отметить, что в рассматриваемых условиях полета осесимметричное степенное тело с оптимальным показателем степени $m=0.7$ и пятикратным удлинением имеет коэффициент волнового сопротивления $C x \approx 0.019$ [22]. При радиусе миделя $\mathrm{Ra} \approx 33$ см его аэродинамическое сопротивление $F_{d} \approx 3810 \mathrm{H}$. С учетом того, что коэффициент сопротивления в [22] определяется по избыточному давлению, тяга рассматриваемой силовой установки более чем в полтора раза превышает это сопротивление. Тяга установки, пересчитанная по избыточному давлению, составляет примерно 0.642 т $\approx 6292 \mathrm{H}$. 
Наряду с тягой и удельным импульсом интерес представляет КПД устройства, которое определяется как отношение полезной мощности к затраченной $\eta=W /\left(W_{f}\right)$ [19]. Здесь полезная мощность $W=F \cdot u_{0}$, где $u_{0}$ - скорость набегающего воздушного потока, или полетная скорость; а затраченная - это величина $W_{f}=Q_{\mathrm{H} 2} \cdot G_{\mathrm{H} 2}$ - мощность, которая снимается при сгорании всего инжектируемого водорода, $G_{\mathrm{H} 2}-$ расход водорода, $Q_{\mathrm{H} 2}-$ удельная теплота сгорания водорода, или теплота сгорания единицы массы водорода. Возможны различные варианты определения $Q_{\mathrm{H} 2}$, поскольку эта величина меняется в зависимости от условий и режима сжигания топлива.
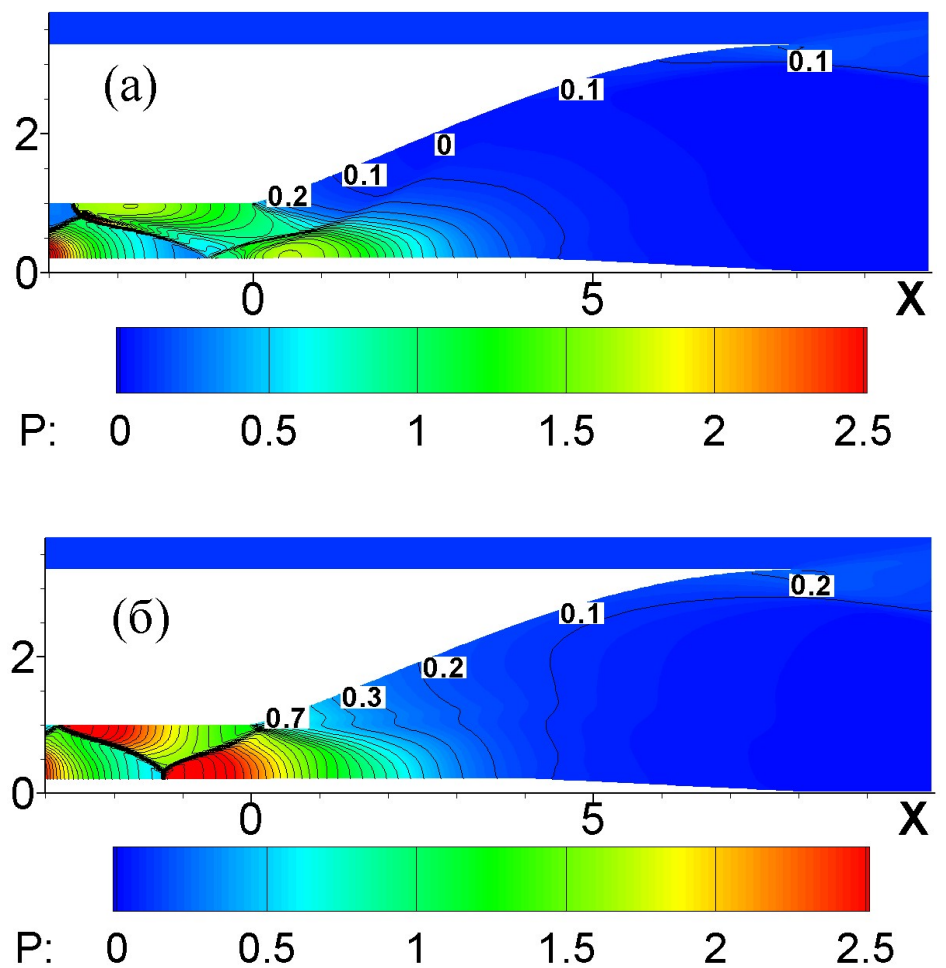

Рис. 16. Давление в области сопла в отсутствии горения (а) и при сжигании водорода (б)

В данной работе выбирается теплота сжигания водорода в составе стехиометрической смеси при нормальном атмосферном давлении и температуре $300 \mathrm{~K}$. Удельная теплота сгорания стехиометрической водородовоздушной смеси $Q$ в детонационной волне Чепмена-Жуге равна 3.7854, при постоянном объеме $Q=3.6174$ и постоянном давлении $Q=3.7146$ МДж/кг. Это результаты расчета с учетом неполноты сгорания по программе GASEQ, опубликованной в интернете в открытом доступе [20]. В наименее благоприятном случае для расчета КПД $Q \approx 3.7854$ МДж/кг, а $Q_{\mathrm{H} 2} \approx Q / 0.055=68.8253$ МДж/кг. На высоте 16 км при $\mathrm{M}_{0}=9$ полетная скорость $u_{0} \approx 2655 \mathrm{~m} / \mathrm{c}$. Полезная мощность $W=F \cdot u_{0} \approx 21.492$ МВт, а КПД $\eta \approx 35 \%$, несмотря на далеко не полное сгорание водорода. В аналогичных условиях полета детонационный двигатель с прямоточной сопловой камерой сгорания [21] имеет почти в четыре раза меньшие значения удельного импульса, удельной тяги и КПД: $\boldsymbol{I}_{G} \approx 13.4 \mathrm{c}, \boldsymbol{I} \approx 244 \mathrm{c}, \eta \approx 9.3 \%$.

\section{3. Расчет по схеме первого порядка}

Несмотря на возможность вдвое увеличить шаг по времени, продолжительность расчета по схеме первого порядка на сетке с увеличенным в $3 \div 4$ раза числом расчетных ячеек по каждому направлению вырастает примерно в $15 \div 30$ раз. Расчет по схеме первого порядка на основной сетке сильно завышает расход газа, его продолжение в задаче с инжекцией водорода не имеет смысла. Поэтому в данной работе расчет течения с инжекцией водорода по схеме 
первого порядка продолжает решение, полученное в подобластях $2 \div 5$ по схеме второго порядка точности до момента подачи водорода. Погрешность вычисления массового расхода газа после перфорированного участка продольной стенки камеры сгорания $(X \geq-4.8)$ по схеме первого порядка не превышает $1.5 \%$. В случае схемы второго порядка ошибка не превышает $0.2 \%$.

По схеме первого порядка течение имеет более размытую ударно-волновую структуру течения (см. рис. $8, \sigma-12, \sigma)$, однако вихревое образование за торцевой стенкой камеры сгорания сохраняется. Несгоревшая доля водорода составляет примерно 58 \%, что говорит о более полном сгорании по сравнению с расчетом по схеме второго порядка. Давление у торцевой стенки кормы оказывается ниже, чем в случае схемы второго порядка (см. рис. 8), но выше в области сопла (рис. 17), что обеспечивает более высокие значения тяги и удельного импульса: $\boldsymbol{F} \approx 1.0278$ т, $\boldsymbol{I}_{G} \approx 61.5 \mathrm{c}, \boldsymbol{I} \approx 1154.8$ с (см. рис. 14 , кривые 2 ). При этом КПД увеличивается почти до $45 \%$.

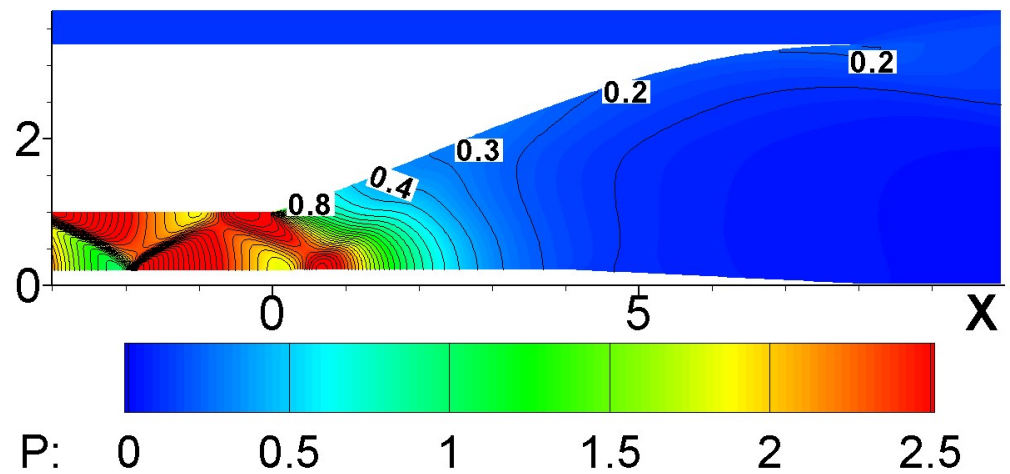

Рис. 17. Давление в области сопла по схеме первого порядка

Таким образом, более интенсивная диффузия, характерная для расчетов по схеме первого порядка, обеспечивает заметный рост силовых характеристик и КПД рассматриваемого устройства.

\section{5. Заключение}

В предлагаемой схеме силовой установки, расположенной за кормой сверхзвукового летательного аппарата, сжигание водорода происходит, в основном, в диффузионном режиме. В численном эксперименте показано, что двигатель способен работать в установившемся режиме и обеспечивать полет широкого класса осесимметричных тел на высоте порядка 16 км с число Маха равным 9. В этих условиях КПД, удельная тяга и удельный импульс в разы выше, чем у детонационного двигателя с прямоточной сопловой камерой сгорания.

\section{Благодарности и ссылки на гранты}

Работа выполнена при финансовой поддержке международного гранта РФФИ № 20-51-00003 (Бел_а).

\section{Литература}

1. Hinkey, J. B., Williams, J. T., Henderson, S. E., and Bussing, T. R. A. Rotary-Valved, Multiple-Cycle, Pulse Detonation Engine Experimental Demonstration // AIAA Paper 97-2746. 1997.

2. Bussing, T. R. A. Rotary Valve Multiple Combustor Pulse Detonation Engine// U.S. Patent Number 5345758, Sept. 13, 1994.

3. Ma F., Choi J-Y., Yang V. Thrust Chamber Dynamics and Propulsive Performance of Single-Tube Pulse Detonation Engines// AIAA paper. 2004-0865. 2004. 
4. Ma F., Jeong-Yeol Choi J-Y., Yang V. Thrust Chamber Dynamics and Propulsive Performance of Multitube Pulse Detonation Engines//Journal of propulsion and power. 2005. Vol. 21, No. 4. Pp. 681-691.

5. Eidelman S., Grossmann W., Lottati I. Computational Analysis of Pulsed Detonation Engines and Applications//AIAA Paper 90-0460. 1990. 13 p.

6. Зельдович Я.Б. К вопросу об энергетическом использовании детонационного горения // Журнал технической физики. 1940. Т.10. № 17. С. 1453-1461.

7. Туник Ю.В. Детонационное горение водорода в сопле Лаваля с центральным коаксиальным цилиндром// Изв. РАН. МЖГ. 2014. № 5. С. 142-148.

8. Туник Ю.В. Запуск сопла в набегающем потоке// Изв. РАН. МЖГ. 2011. № 5. С. 106-113.

9. З Зубин М.А., Туник Ю.В. Запуск осесимметричного сопла Лаваля в гиперзвуковом потоке// Изв. РАН. МЖГ. 2014. № 4. С. 155-160.

10. Годунов С.К. Разностный метод численного расчета разрывных решений уравнений гидродинамики // Математический сборник. 1959. Т. 47(89), № 3. С. 271-306.

11. Туник Ю.В. Численное решение тестовых задач на основе модифицированной схемы С.К. Годунова // Журнал вычислительной математики и математической физики. 2018. Т. 58. № 10. С. $1629-1641$.

12. Туник Ю.В. Проблемы численного моделирования на основе некоторых модификаций схемы Годунова //Физико-химическая кинетика в газовой динамике. 2018. Т. 19, № 1.С.1-11.

13. Белоцерковский О.М. Численное моделирование в механике сплошных сред. М. Наука. 1994. $442 \mathrm{c}$.

14. Азатян В.В., Андрианова 3.С., Иванова А.Н. Моделирование ингибирования распространения пламени в водородовоздушной среде// Кинетика и катализ. 2012. Т. 51. № 4. С. 461-468.

15. Азатян В.В., Андрианова 3.С., Борисов А.А., Иванова А.Н. Основные реакции, определяющие тепловыделение в процессе горения водорода с кислородом// Кинетика и катализ. 2012. Т. 53. № 6. C. 683-689.

16. Варнатц Ю., Маас У., Диббл Р. Горение. Физические и химические аспекты, моделирование, эксперименты, образование загрязняющих веществ/ Пер. с англ. Г.Л. Агафонова. Под ред. П.А. Власова. - М.: Физматлит, 2003. - 352 с.

17. Starik A.M., Titova N.S., Sharipov A.S. Kinetic mechanism of H2-O2 ignition promoted by singlet oxygen $\mathrm{O} 2(\mathrm{a} 1 \Delta \mathrm{g}) / /$ Deflagrative and detonative combustion / Ed. by G.D. Roy, S.M. Frolov. Torus 19-Press. Moscow, 2010. Pp. 12-19.

18. Гурвич Л.В., Вейц И.В., Медведев В.А. и др. Термодинамические свойства индивидуальных веществ. Справочник. Т.1. Кн.2. М.: Наука. 1978. 327 с.

19. Седов Л.И. Механика сплошной среды. Т. 2. Москва. Наука. 1970. 568 с.

20. Morley C. Gaseq: A Chemical Equilibrium Program for Windows. Version 0.79. -2005. http://www.gaseq.co.uk

21. Зубин М.А., Туник Ю.В. О стабилизации детонационного горения водорода в сопле Лаваля// Физико-химическая кинетика в газовой динамике. 2015. Том 16, вып. 3. http://chemphys.edu.ru/issues/2015-16-3/articles/579/

22. Аэромеханика сверхзвукового обтекания тел вращения степенной формы. Под ред. д-ра физмат. наук проф. Г.Л. Гродзовского. М., Машиностроение, 1975, 184 с.

\section{References}

1. Hinkey, J. B., Williams, J. T., Henderson, S. E., and Bussing, T. R. A., "Rotary-Valved, MultipleCycle, Pulse Detonation Engine Experimental Demonstration," 35th Aerospace Sciences Meeting \& Exhibit, AIAA Paper 97-2746, Jan. 1997. 
2. Bussing, T. R. A., "Rotary Valve Multiple Combustor Pulse Detonation Engine," Patent US 5345758, 13.09.1994.

3. Ma, F., Choi, J-Y., Yang, V., "Thrust Chamber Dynamics and Propulsive Performance of Single-Tube Pulse Detonation Engines," 42nd AIAA Aerospace Sciences Meeting and Exhibit, AIAA Paper. 20040865, Jan. 2004.

4. Ma, F., Jeong-Yeol, Choi, J-Y., Yang, V., "Thrust Chamber Dynamics and Propulsive Performance of Multitube Pulse Detonation Engines," Journal of Propulsion and Power. Vol. 21, No. 4, 2005, pp. 681-691.

5. Eidelman S., Grossmann W., Lottati I. Computational Analysis of Pulsed Detonation Engines and Applications," 28th Aerospace Sciences Meeting, AIAA Paper 90-0460, Jan. 1990.

6. Zel'dovich, Ja. B., "K voprosu ob jenergeticheskom ispol'zovanii detonacionnogo gorenija," Zhurnal tehnicheskoj fiziki, Vol. 10, No. 17, 1940, pp. 1453-1461.

7. Tunik, Ju. V., "Detonacionnoe gorenie vodoroda v sople Lavalja s central'nym koaksial'nym cilindrom," Izv. RAN. MZhG, No. 5, 2014, pp. 142-148.

8. Tunik, Ju. V., "Zapusk sopla v nabegajushhem potoke," Izv. RAN. MZhG, No. 5, 2011, pp. 106-113.

9. Zubin, M. A., Tunik, Ju. V., "Zapusk osesimmetrichnogo sopla Lavalja v giperzvukovom potoke,” Izv. RAN. MZhG, No. 4, 2014, pp. 155-160.

10. Godunov, S. K., "Raznostnyj metod chislennogo rascheta razryvnyh reshenij uravnenij gidrodinamiki," Matematicheskij Sbornik, Vol. 47(89), No. 3, 1959, pp. 271-306.

11. Tunik, Ju. V., "Chislennoe reshenie testovyh zadach na osnove modificirovannoj shemy S.K. Godunova," Zhurnal Vychislitel'noj Matematiki i Matematicheskoj Fiziki, Vol. 58, No. 10, 2018, pp. 1629-1641.

12. Tunik, Ju. V., "Problemy chislennogo modelirovanija na osnove nekotoryh modifikacij shemy Godunova," Fiziko-himicheskaja kinetika v gazovoj dinamike (Physical-Chemical Kinetics in Gas Dynamics), Vol. 19, No.1, 2018. http://chemphys.edu.ru/issues/2018-19-1/articles/701/

13. Belocerkovskij, O. M., Chislennoe modelirovanie $v$ mehanike sploshnyh sred (Numerical Modeling in Fluid Dynamics), M.: Nauka, 1994, 442 p.

14. Azatjan, V. V., Andrianova, Z. S., Ivanova, A. N., "Modelirovanie ingibirovanija rasprostranenija plameni v vodorodovozdushnoj srede," Kinetika i kataliz, Vol. 51, No. 4, 2012, pp. 461-468.

15. Azatjan, V. V., Andrianova, Z. S., Borisov, A. A., Ivanova, A. N., "Osnovnye reakcii, opredeljajushhie teplovydelenie v processe gorenija vodoroda s kislorodom," Kinetika i kataliz, Vol. 53, No. 6, 2012, pp. 683-689.

16. Varnatc, Ju., Maas, U., Dibbl, R. Gorenie. Fizicheskie i himicheskie aspekty, modelirovanie, jeksperimenty, obrazovanie zagrjaznjajushhih veshhestv (Combustion. Physical and chemical aspects, modeling, experiments, formation of pollutants), Per. s angl. G.L. Agafonova. Ed. by P.A. Vlasova. M.: Fizmatlit, 2003, 352 p.

17. Starik, A. M., Titova, N. S., Sharipov, A. S., Kinetic mechanism of H2-O2 ignition promoted by singlet oxygen O2(a1 $\Delta \mathrm{g}) / /$ Deflagrative and detonative combustion, Ed. by G.D. Roy, S.M. Frolov. Torus 19-Press, Moscow, 2010, pp. 12-19.

18. Gurvich, L. V., Vejc, I. V., Medvedev, V. A., et al. Termodinamicheskie svojstva individual'nyh veshhestv. Spravochnik (Thermodynamic properties of individual substances. Handbook), Vol.1, No. 2. M.: Nauka, 1978, 327 p.

19. Sedov, L. I. Mehanika sploshnoj sredy (Continuum Mechanics), Vol. 2, M.: Nauka, 1970, 568.

20. Morley, C., Gaseq: A Chemical Equilibrium Program for Windows, Version 0.79, 2005, http://www.gaseq.co.uk

21. Zubin, M. A., Tunik, Ju. V., "O stabilizacii detonacionnogo gorenija vodoroda v sople Lavalja," Fiziko-himicheskaja kinetika v gazovoj dinamike (Physical-Chemical Kinetics in Gas Dynamics), Vol. 16, No. 3, 2015. http://chemphys.edu.ru/issues/2015-16-3/articles/579/ 
22. Ajeromehanika sverhzvukovogo obtekanija tel vrashhenija stepennoj formy (Aeromechanics of supersonic flow around power-law bodies of rotation), Ed. by Dr. Phys\&Math sci. Prof. G.L. Grodzovskii. M., Mashinostroenie, 1975, 184 p.

Статья поступила в редакцию 14 сентября 2020 г. 